\title{
Axonal electrovisiogram or inverse photopic skin electroretinogram?
}

\section{Eletrovisograma axonal ou eletrorretinograma fotópico inverso de pele?}

Katharina Messias ${ }^{1}$, Vinicius Monteiro de Castro $^{1}$, Florian Gekeler ${ }^{2}$, Andre Messias ${ }^{1}$

\section{Dear Editor,}

We would like to discuss the very interesting article "Axonal electrovisiogram as an electrophysiological test to evaluate optic nerve and inner retina electrical potentials: findings in normal subjects", published in the 74(1) issue of Arquivos Brasileiros de Oftalmologia(1).

In this work, authors recorded electrophysiological potentials using the Axonal electrovisiogram (AxEvg) paradigm, which is a method developed by Sabadel et al.(2), to record pre-chiasmatic electric potentials, in normal subjects.

The study is well designed and is nicely reported in the article, but some major concerns must be made about the origin of these electrical responses.

In this experiment an interference of retinal electric potentials - the electroretinogram (ERG) - cannot be ruled out, since AxEvg is recorded with electrodes placed very closely to the eye, in a similar configuration used for skin ERG (sERG)(3,4).

Interestingly, the difference between electrode placement for AxEvg and sERG is that the electrode placed closest to the eye is the negative pole, which might explain the waveform configuration found in AxEvg recordings. Figure 1 shows electrode placements for AxEvg and sERG.
In matter of fact, placing the negative pole as the closest electrode to the eye, regardless of the position of the positive pole (placed on ear lobe in case of AxEvg or placed below the eye in case of sERG), and stimulating the retina with a strong light flash $\left(2.5 \mathrm{~cd} . \mathrm{s} / \mathrm{m}^{2}\right)$ using a Ganzfeld bowl, one cannot avoid the hypothesis of the electrical response to be generated by the retina and presenting as an ERG with inverse polarity.

Interestingly, the waveform shown by Cella et al.(1), presents the same characteristics of a photopic ERG response, but recorded with inverse polarity, with $\mathrm{P} 1$ being the a-wave and N1 the b-wave.

To investigate the origin of these electrical potentials we performed recordings using the same electrode configuration and stimulus parameters used by Cella et al. in a patient with optic chiasm dissection after a tuberculum sellae meningioma surgery 1 year earlier (no light perceptions in both eyes ever since). To proof the retinal origin of the AxEvg the electrodes in left eye were placed as mentioned by Cella at al., whereas, the electrodes in right eye were placed at the conjunctiva (DTL electrodes were used as negative pole) and at the earlobe (positive pole) (demonstrated in Figure 1). Two single flash stimulus intensities were used to proof relationship between stimulus intensity and amplitude. Finally, $30 \mathrm{~Hz}$ flicker was performed.
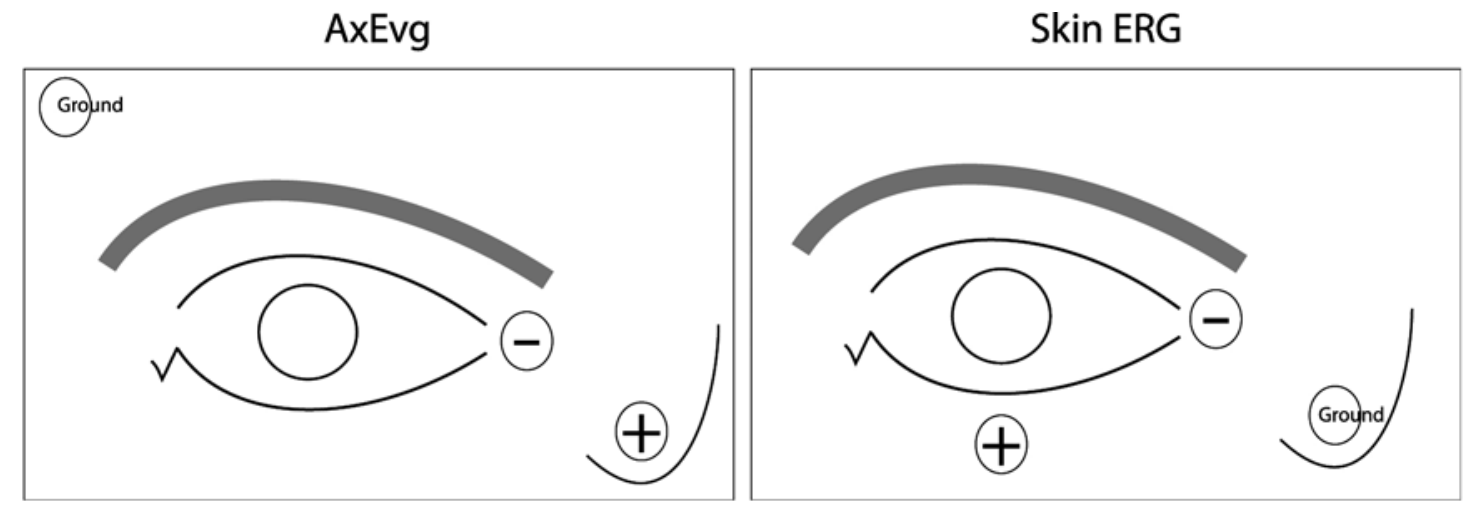

Figure 1. Electrode placement for AxEvg and sERG. (Left) AxEvg: ground electrode is placed on patient's forehead, negative electrode at the outer eye canthus and positive electrode at ipsilateral earlobe. (Right) $s E R G$ : ground electrode is placed at earlobe, negative electrode is placed at outer eye canthus and the positive electrode is placed below the eye.

${ }^{1}$ Department of Ophthalmology, Otorhinolaryngology and Head and Neck Surgery, School of Medicine of Ribeirão Preto - Universidade de São Paulo - USP - Ribeirão Preto (SP), Brazil.

Funding: No specific financial support was available for this study. Disclosure of potential conflicts of interest: K.Messias, None; V.M.de castro, None; F.Gekeler, None; A.Messias, None. 

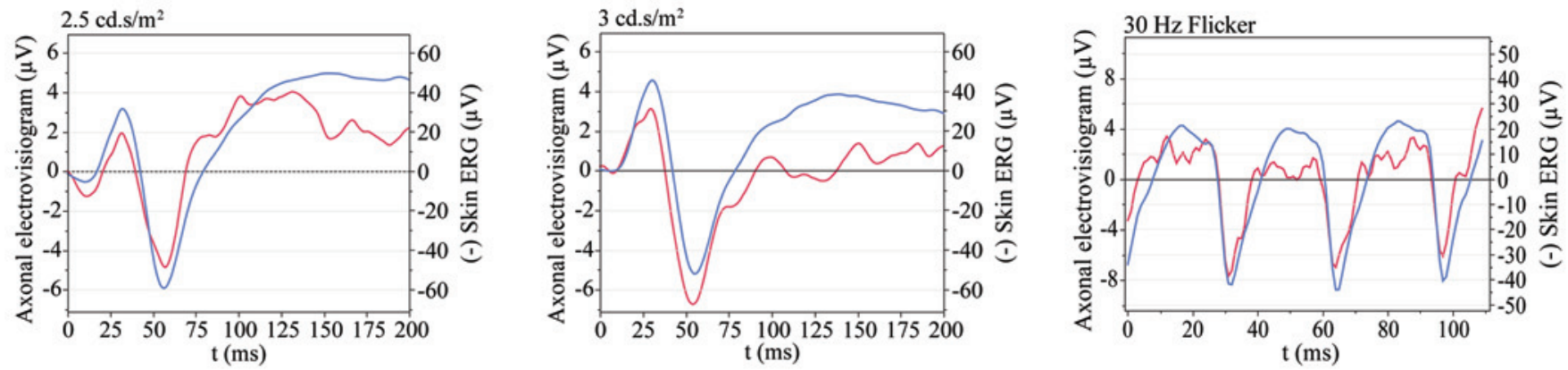

Axonal electrovisiogram $(\mu \mathrm{V})$

(-) Skin ERG $(\mu \mathrm{V})$

Figure 2. Potentials recorded from patient with dissected chiasm using AxEvg (red line) and inverted sERG techniques (blue line). (Top) 2.5 cd.s $/ \mathrm{m}^{2}$ stimulus; (Middle) 3 cd.s $/ \mathrm{m}^{2}$ stimulus; (Bottom) $30 \mathrm{~Hz}$ Flicker stimulus.

Interestingly, we can observe the same potential configuration, in both eyes even though we performed the AxEvg in the left eye and a modified SERG in the right eye. Latencies for P1 and N1 are corresponding in both eyes (see Figure 2). Because of the greater spatial proximity of the DTL electrode to the retina, amplitudes in the right eye are higher when compared to left eye. As the patient does not posses any functional optic nerve at neither of both sides, the only explicable origin of the measured potentials must be the retina. As we placed the negative electrode in contact with the eye rather than the positive, as it is use in ERG recording, we have a negative potential configuration. Note the corresponding latencies of the inverted ERG in figure 2. Furthermore, we can observe stimulus intensity correlation of the recorded potential, which speaks strongly in favor for electroretinographic origin of the measured potential.

In conclusion, this data shows that the recorded electrical potentials using electrode placement proposed by Sabadel et al. ${ }^{(2)}$, for assessment of pre-chiasmatical potentials or evaluation of optic nerve function, and carried out by Cella et al. ${ }^{(1)}$, originate in the retina and are not optic nerve potentials. Future users should be aware of the electrical potentials generation to better understand its applications.
The normative data shown by Cella et al., is still very valuable, since sERG can be very useful, especially for retinal function evaluation in children.

With kind regards,

Katharina Messias
Vinicius de Castro
Florian Gekeler
André Messias

\section{REFERENCES}

1. Cella W, Dantas AM, Lima AV, Avila MP. Axonal electrovisiogram as an electrophysiological test to evaluate optic nerve and inner retina electrical potentials: findings in normal subjects. Arq Bras Oftalmol. 2011;74(1):37-43.

2. Sabadel A, Dalens H, Sole P. [Axonal electrovisiogram. Recording technic-clinical value]. Bull Soc Ophtalmol Fr. 1983:83(5):739-44. French.

3. Giltrow-Tyler JF, Crews SJ, Drasdo N. Electroretinography with noncorneal and corneal electrodes. Invest Ophthalmol Vis Sci. 1978;17(11):1124-27.

4. McCulloch DL, Van Boemel GB, Borchert MS. Comparisons of contact lens, foil, fiber and skin electrodes for patterns electroretinograms. Doc Ophthalmol. 1997;94(4): 327-40. 